\title{
Expectations of Patients with a Diagnosis of Breast Cancer When Meeting the Psycho-Oncologist: Beyond the Assistance of the Oncologist
}

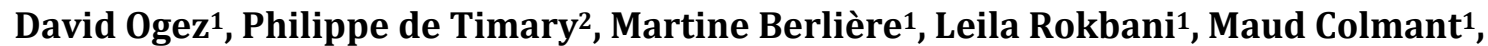 \\ Frédérique Lieutenant1, Guillaume Gascard1, Catherine Denoel1, Aline van Maanen1, \\ Emmanuelle Zech ${ }^{3}$ \\ ${ }^{1}$ Cancer Center, Cliniques Universitaires St Luc, Brussels, Belgium \\ ${ }^{2}$ Adult Psychiatry, Cliniques Universitaires St Luc, Brussels, Belgium \\ ${ }^{3}$ Faculty of Psychology and Education Sciences, Université Catholique de Louvain, Louvain-la-Neuve, Belgium \\ Email: david.ogez@uclouvain.be
}

Received 3 July 2014; revised 3 August 2014; accepted 3 September 2014

Copyright (C) 2014 by authors and Scientific Research Publishing Inc. This work is licensed under the Creative Commons Attribution International License (CC BY). http://creativecommons.org/licenses/by/4.0/

(c) (;) Open Access

\section{Abstract}

Objective: Cancer patients consider the oncologist as their main resource insofar as the medical needs generally take precedence over psychological needs. Nevertheless, the psychological intervention is also important. The systematic consultation implemented in our hospital after a diagnosis of cancer is a manner to answer patients' psychological needs. In a survey, we assessed the satisfaction and expectations of the patients about this consultation. Methods: One year after a diagnosis of breast cancer, 104 patients answered a retrospective questionnaire assessing: sociodemographic data, cancer medical information, systematic consultation satisfaction, patients' expectations for a systematic intervention, and patients' characteristics who began a psychological follow-up. Results: $\mathbf{7 2 . 1 \%}$ of the patients were satisfied with having the opportunity to consult a psychologist during a systematic consultation after cancer diagnosis. Their expectations were to have opportunities of emotional expression, reassurance, obtaining additional medical information, talking about their fear over additional treatments, and identifying further support. $28.8 \%$ of the patients re-contacted the psychologist for further help after the systematic consultation. They were significantly younger $(p<0.001)$ than the others. Conclusions: Besides the importance of support by medical specialists [1], offering the opportunity to breast cancer patients to discuss inner feelings and treatment expectations during a systematic psychological consultation was useful for most of them. About one third of the patients asked for a further consultation with a psychologist after a first systematic consultation, especially younger patients. This stressed the importance 
of the role of psychologists for psycho-social support of the patient after cancer treatment.

\title{
Keywords
}

\author{
Psycho-Oncology, Screening, Consultation, Systematic, Psychological Follow-Up, Breast Cancer, \\ Survey
}

\section{Introduction}

Cancer patients most often consider the oncologist as their main resource in order to answer their needs in oncological situations [1]. Indeed, when it comes to cancer, the medical needs generally take prevalence over psychological needs. Pain [2], fatigue [3], and nausea [4] are among the most frequent symptoms expressed during cancer treatment and are generally difficult to manage by most patients. However, patients also frequently report and express psychological distress [5] [6], most often to the specialist physician in charge of their treatment [7]-[9]. Surveys have shown that the patients' psychological needs will mainly concern difficulties that they feel during medical interactions and lack of communication about their cancer and treatment, as well as psychological symptoms such as worries about the disease [10] [11].

Therefore, besides medical intervention, the psychological intervention of the oncologist is of paramount importance. In conjunction to the oncologist's intervention, psychologists have developed specific skills to listen to patients during their oncological treatment [12], to support their emotional regulation abilities [13] [14], and to evaluate the possible occurrence of psychopathological comorbidities or coincidences [15]-[17]. To answer cancer patients' specific needs, the Belgian National Cancer Plan [18] has supported and financed the development of psycho-oncological support teams in all oncological centres across Belgium. Shortly after the implementation of the Belgian National Cancer Plan, we thus decided to investigate the characteristics of the population that consults the psycho-oncologist and the expectations toward this consultation. Up to now, psycho-oncological interventions are either supportive clinical interviews, with no systematic questioning of the expectations of patients [19], or totally structured interviews with systematic check lists [20]. The systematic consultation is an intermediate semi-directive method that has been implemented in our hospital. It occurs within 7 days after a diagnosis of cancer has been established and provided to the patient. This consultation is seen as a way to answer cancer patients' psychological needs [21]. The systematic consultation includes 1) a reciprocal presentation; 2) an anamnesis of the patient (family and professional life), his/her medical history, and his/her potential psychological difficulties; 3) an evaluation of the patient's level of psychological distress and adaptation skills; 4) a discussion about the patient's expectations concerning an eventual psychological follow-up.

In this paper, the evaluation of this systematic consultation is performed. Therefore, the aim of the survey is to evaluate 1) the patients' satisfaction one year after they have their systematic consultation; 2) the profile of the patients who begin a psychological follow-up during that year; 3) patients' suggestions with regard to potential improvements for the systematic consultation ${ }^{1}$.

\section{Survey Procedure and Respondents}

\subsection{Procedure}

Each female patient consulting for a breast cancer surgery between January and December 2009 met a psychologist for a systematic consultation. One year after the consultation, a questionnaire was sent to their home with a stamped envelope for sending it back. The questionnaire was anonymous and patients were therefore free to answer it or not. All patients were French-speaking. There was otherwise no exclusion criterium. The ethical committee of our academic hospital had accepted the study.

\subsection{Respondents}

Out of the 160 breast cancer patients to whom the questionnaire was sent, $104(65.0 \%)$ returned the surveys

\footnotetext{
${ }^{1}$ The results of this survey were presented in the 13th congress of international psycho-oncology society and the 2012 conference of Canadian association of psycho-oncology.
} 
back. Table 1 shows the socio-demographic characteristics of the patients studied. The average age of responding patients was 60.0 years old $(\mathrm{SD}=11.62)$. Fifty-two $(50.0 \%)$ women were aged 60 or under and $50(48.1 \%)$ were over 60 years old. Concerning their marital status, $69(66.3 \%)$ women were married or in couple and 85 (83.7\%) had at least 1 child. Seventy-three (70.2\%) were living with at least one person, while $29(27.9 \%)$ were living alone. Finally, 40 (38.5\%) women had a full-time or part-time job, while 57 (54.8\%) had temporarily stopped their professional activity or were unemployed.

Table 1. Demographic information, overall and by re-contact type.

\begin{tabular}{|c|c|c|c|c|}
\hline Characteristics & Re-contact $\mathrm{n}=30$ & No re-contact $\mathrm{n}=74$ & Total $n=104$ & p-value ${ }^{1}$ \\
\hline \multicolumn{5}{|l|}{ Age (years) } \\
\hline $\mathrm{n}$ & 29 & 73 & 102 & \multirow[t]{6}{*}{$<0.001^{\mathrm{a}}$} \\
\hline Mean & 54.0 & 62.4 & 60.0 & \\
\hline SD & 9.51 & 11.6 & 11.62 & \\
\hline Min & 28 & 38 & 28 & \\
\hline $\operatorname{Max}$ & 71 & 87 & 87 & \\
\hline Missing & 1 & 1 & 2 & \\
\hline \multicolumn{5}{|l|}{ Age category, $\mathrm{n}(\%)$} \\
\hline$\leq 60$ years & $21(70.0)$ & $31(41.9)$ & $52(50.0)$ & \multirow[t]{3}{*}{$0.008^{\mathrm{b}}$} \\
\hline$>60$ years & $8(26.7)$ & $42(56.8)$ & $50(48.1)$ & \\
\hline Missing & $1(3.3)$ & $1(1.3)$ & $2(1.9)$ & \\
\hline \multicolumn{5}{|l|}{ Marital status, n (\%) } \\
\hline In couple & $22(73.3)$ & $47(63.5)$ & $69(66.3)$ & \multirow[t]{3}{*}{$0.189^{\mathrm{b}}$} \\
\hline Alone & $7(23.3)$ & $26(35.1)$ & $33(31.7)$ & \\
\hline Missing & $1(3.3)$ & $1(1.3)$ & $2(1.9)$ & \\
\hline \multicolumn{5}{|l|}{ Living environment, $\mathrm{n}(\%)$} \\
\hline Accompagned & $23(76.7)$ & $50(67.6)$ & $73(70.2)$ & \multirow[t]{3}{*}{$0.336^{\mathrm{b}}$} \\
\hline Alone & $6(20.0)$ & $23(31.1)$ & $29(27.9)$ & \\
\hline Missing & $1(3.3)$ & $1(1.3)$ & $2(1.9)$ & \\
\hline \multicolumn{5}{|l|}{ Children, n (\%) } \\
\hline 0 & $2(6.7)$ & $14(18.9)$ & $16(15.4)$ & \multirow[t]{6}{*}{$0.159^{c}$} \\
\hline 1 & $7(23.3)$ & $16(21.6)$ & $23(22.1)$ & \\
\hline 2 & $15(50.0)$ & $23(31.1)$ & $38(36.5)$ & \\
\hline 3 & $2(6.7)$ & $14(18.9)$ & $16(15.4)$ & \\
\hline$\geq 4$ & $3(10.0)$ & $5(6.8)$ & $8(7.7)$ & \\
\hline Missing & $1(3.3)$ & $2(2.6)$ & $3(2.9)$ & \\
\hline \multicolumn{5}{|l|}{ Professional Activity, n (\%) } \\
\hline \multicolumn{5}{|l|}{ Yes } \\
\hline Full time & $8(26.7)$ & $14(18.9)$ & $22(21.2)$ & \multirow[t]{2}{*}{$0.085^{\mathrm{c}}$} \\
\hline Part time & $9(30.0)$ & $9(12.2)$ & $18(17.3)$ & \\
\hline \multicolumn{5}{|l|}{ No } \\
\hline Temporarily interrupted & $1(3.3)$ & $5(6.8)$ & $6(5.8)$ & \\
\hline No activity & $12(40.0)$ & $45(60.8)$ & $57(54.8)$ & \\
\hline Missing & 0 & $1(1.3)$ & $1(1.0)$ & \\
\hline
\end{tabular}

${ }^{1} \mathrm{P}$-value obtained from unpaired $t$-test $\mathrm{t}^{\mathrm{a}}$; Fisher Exact test ${ }^{\mathrm{b}}$ and Chi-Square test $\mathrm{t}^{\mathrm{c}}$. 
Table 2 shows the medical aspects related to their cancer. Forty-six (44.2\%) patients had a no history of cancer, $39(37.5 \%)$ had a family history of the disease, $10(9.6 \%)$ had a personal history of cancer, and $8(7.7 \%)$ had both a family and a personal oncological history. Most cancers $(61.5 \%)$ were detected through a systematic screening. Regarding treatments, 58 (55.8\%) women underwent a mastectomy and $43(41.3 \%)$ had a tumerectomy. In addition to surgery, 45 (43.3\%) patients had a combined regimen of chemotherapy and radiotherapy, 35 (33.7\%) had radiotherapy alone, and $11(10.6 \%)$ had a chemotherapy treatment alone. Only $5(4.8 \%)$ patients did not receive any additional treatment.

\subsection{Survey Questionnaire}

The home made questionnaire consisted of 5 parts. The first dealt with the socio-demographic aspects of the population including gender, age, cultural background, marital status, family, and employment status. The second part included information on cancer (personal or family history of cancer, cancer diagnosis) and medical treatments (nature of surgical intervention, additional treatments). The third part dealt with the evaluation of the satisfaction of the systematic consultation (quality of contact with the psychologist, timing of this initial contact, i.e., at surgery, and proposition of a systematic consultation). This evaluation was done using 5-point Likert

Table 2. Cancer information, overall and by re-contact type.

\begin{tabular}{|c|c|c|c|c|}
\hline Characteristics & Re-contact $n=30$ & No re-contact $n=74$ & Total $n=104$ & p-value ${ }^{1}$ \\
\hline \multicolumn{5}{|l|}{ History of cancer, n (\%) } \\
\hline No history & $12(40.0)$ & $34(45.9)$ & $46(44.2)$ & $0.329^{b}$ \\
\hline Family & $12(40.0)$ & $27(36.5)$ & $39(37.5)$ & \\
\hline Personal & $5(16.7)$ & $5(6.8)$ & $10(9.6)$ & \\
\hline Personal and family & $1(3.3)$ & $7(9.5)$ & $8(7.7)$ & \\
\hline Missing & 0 & $1(1.3)$ & $1(1.0)$ & \\
\hline \multicolumn{5}{|l|}{ Discovery Cancer, n (\%) } \\
\hline Systematic screening & $19(63.3)$ & $45(60.8)$ & $64(61.5)$ & $0.407^{\mathrm{b}}$ \\
\hline Self discovery & $9(30.0)$ & $17(23.0)$ & $26(25.0)$ & \\
\hline Other & $1(3.3)$ & $8(10.8)$ & $9(8.7)$ & \\
\hline Missing & $1(3.3)$ & $4(5.4)$ & $5(4.8)$ & \\
\hline \multicolumn{5}{|l|}{ Surgery, n (\%) } \\
\hline Mastectomy & $15(50.0)$ & $43(58.1)$ & $58(55.8)$ & $0.396^{\mathrm{a}}$ \\
\hline Tumerectomy & $13(43.3)$ & $30(40.5)$ & $43(41.3)$ & \\
\hline Missing & $2(6.7)$ & $1(1.3)$ & $3(2.9)$ & \\
\hline \multicolumn{5}{|l|}{ Additional treatment, n (\%) } \\
\hline Chemotherapy + Radiotherapy & $11(36.7)$ & $34(45.9)$ & $45(43.3)$ & $0.327^{\mathrm{b}}$ \\
\hline Radiotherapy alone & $9(30.0)$ & $26(35.1)$ & $35(33.7)$ & \\
\hline Chemotherapy alone & $6(20.0)$ & $5(6.8)$ & $11(10.6)$ & \\
\hline Other & $1(3.3)$ & $4(5.4)$ & $5(4.8)$ & \\
\hline None & $2(6.7)$ & $3(4.1)$ & $5(4.8)$ & \\
\hline Missing & $1(3.3)$ & $2(2.7)$ & $3(2.9)$ & \\
\hline
\end{tabular}

${ }^{1}$ p-value obtained from Fisher Exact test ${ }^{\mathrm{a}}$ and Chi-Square test ${ }^{\mathrm{b}}$. 
scales, ranging from "very satisfied" to "very unsatisfied". The fourth part included the patients' attitudes toward the psychologist following the systematic interview: 1) Did the patient re-contact the psychologist? 2) What motivated their request for a counselling? 3) How many sessions did they have? 4) At what time did they ask for that counselling? 5) If they did not have a contact, what motivated their choice not to contact the psychologist?

The last part dealt with the patients' expectations from a systematic intervention, and were assessed using a 5-point Likert scales ranging from "very important" to "not important at all": 1) assurance of support and help; 2) possibility to express their feelings over cancer diagnostic; 3) learning ways to communicate the diagnostic to their relatives; 4) freeing themselves from the anguish of the surgery; 5) talking about difficulties over their self-image after the surgery or the treatments; 6) talking about fear of the partner's looking at them and their sexuality; 7) getting further information on the disease and the treatments; 8) looking for reassurance; 9) talking about fear of additional treatments.

\subsection{Statistical Analyses}

Survey results were summarised descriptively. Patient's profile between the 2 groups (those who re-contacted and those who did not re-contact the psychologist after the systematic consultation), were compared using independent $t$-tests, Fisher Exact test, or Chi-square tests as appropriate.

\section{Results}

\subsection{Satisfaction with Systematic Consultation}

With regard to the patient's satisfaction with the systematic consultation, Table 3 shows that out of the 86 $(82.7 \%)$ patients who responded to this question, $62(59.6 \%)$ of them were very satisfied or satisfied with the systematic consultation with the psychologist. Seventeen (16.3\%) were indifferent to it, and only $7(6.7 \%)$ were poorly satisfied or unsatisfied.

Results also showed that 75 (72.1\%) of the women were very satisfied or satisfied with the idea of having the opportunity to consult a psychologist after the diagnosis of cancer. 13 (12.5\%) were indifferent to it. Finally, 64 $(61.5 \%)$ had found that the timing of the first consultation being close to surgery was a good option, while 15 $(14.4 \%)$ were indifferent to it and $11(10.6 \%)$ found it inappropriate.

\subsection{Profile of Patients Who Elected for a Psychological Follow-Up after the Systematic Consultation and Frequency of Further Consultations}

$30(28.8 \%)$ patients had re-contacted the psychologist for further psychological help (Table 1). These patients were significantly younger $(\mathrm{M}=54.0$ years old; $\mathrm{SD}=9.51)$ than those who did not re-contact the psychologist $(\mathrm{M}=62.4 ; \mathrm{SD}=11.6), t(\mathrm{df}=100)=3.459, \mathrm{p}<0.001$. Patients with a professional activity also tended to consult the psychologist more frequently $(\mathrm{n}=40 ; 38.5 \%)$ than those currently unemployed $(\mathrm{n}=63 ; 60.6 \%), \chi^{2}(\mathrm{df}=$ $3)=6.609, p=0.085$. The marital status, the living environment, or the number of children were unrelated to the fact of re-contacting the psychologist (respectively, $\mathrm{p}=0.189,0.336$, and 0.159 ). Their cancer characteristics were also similar. Most patients who had re-contacted the psychologist did so during the medical treatments $(\mathrm{n}=$ $15 ; 50.0 \%)$ or at their end $(\mathrm{n}=7 ; 23.3 \%) .11(36.7 \%)$ patients re-contacted him after a few days, $9(30.0 \%)$ after a few weeks, and $8(26.7 \%)$ after a few months. Most of the patients who had re-contacted the psychologist $(\mathrm{n}=$ $13,43.3 \%)$ attended between 2 to 5 appointments.

As shown in Table 4, 74 (71.2\%) patients decided not to re-contact the psychologist after surgery, although

Table 3. Patient's satisfaction with the systematic consultation.

\begin{tabular}{lcccccc}
\hline & $\begin{array}{c}\text { Very satisfied } \\
\mathrm{n}(\%)\end{array}$ & $\begin{array}{c}\text { Satisfied } \\
\mathrm{n}(\%)\end{array}$ & $\begin{array}{c}\text { Indifferent } \\
\mathrm{n}(\%)\end{array}$ & $\begin{array}{c}\text { Poorly satisfied } \\
\mathrm{n}(\%)\end{array}$ & $\begin{array}{c}\text { Unsatisfied } \\
\mathrm{n}(\%)\end{array}$ & $\begin{array}{c}\text { Total } \mathrm{n}=104 \\
(100 \%)\end{array}$ \\
\hline $\begin{array}{l}\text { Level of global satisfaction } \\
\begin{array}{l}\text { Opinions on systematic appointment } \\
\text { with the psychologist }\end{array}\end{array}$ & $24(23.1)$ & $38(36.5)$ & $17(16.3)$ & $5(4.8)$ & $2(1.9)$ & $86(82.7)$ \\
Appropriate timing of the first appointment & $28(34.7)$ & $39(37.5)$ & $13(12.5)$ & $1(1.0)$ & $3(2.9)$ & $92(88.5)$ \\
\end{tabular}


Table 4. Re-contact and non re-contact information.

\begin{tabular}{|c|c|c|}
\hline Characteristics & Re-contact $\mathrm{n}=30$ & No re-contact $\mathrm{n}=74$ \\
\hline \multicolumn{3}{|l|}{ Thought of re-contact, $\mathrm{n}(\%)$} \\
\hline No & - & $53(71.6)$ \\
\hline Yes & - & $17(23.0)$ \\
\hline Missing & - & $4(5.4)$ \\
\hline \multicolumn{3}{|l|}{ If yes, when? $\mathrm{n}(\%)^{\mathrm{a}}$} \\
\hline During treatment & $15(50.0)$ & $7(41.2)$ \\
\hline At the time of the Screening & $7(23.3)$ & $5(29.4)$ \\
\hline During treatment + Screening & $1(3.3)$ & $2(11.8)$ \\
\hline Other & $6(20.0)$ & $1(5.9)$ \\
\hline Missing & $1(3.3)$ & $2(11.8)$ \\
\hline \multicolumn{3}{|l|}{ If yes, how long after first psychological appointment? $\mathrm{n}(\%)^{\mathrm{a}}$} \\
\hline A few days & $11(36.7)$ & $2(11.8)$ \\
\hline A few weeks & $9(30.0)$ & $5(29.4)$ \\
\hline A few months & $8(26.7)$ & $7(41.2)$ \\
\hline$>1$ year & $1(3.3)$ & 0 \\
\hline Missing & $1(3.3)$ & $3(17.6)$ \\
\hline \multicolumn{3}{|l|}{ If yes, how often did intention come back? $\mathrm{n}(\%)^{\mathrm{a}}$} \\
\hline Not often & - & $5(29.4)$ \\
\hline A few times & - & $5(29.4)$ \\
\hline Punctually & - & $4(23.5)$ \\
\hline Regularly & - & $2(11.8)$ \\
\hline Very often & - & $1(5.9)$ \\
\hline \multicolumn{3}{|l|}{ Reasons for not re-calling, $\mathrm{n}(\%)$} \\
\hline Did not feel need for psychological help & - & $38(51.4)$ \\
\hline Already followed by a psychologist external from the centre & - & $6(8.1)$ \\
\hline Lack of time & - & $5(6.8)$ \\
\hline Contact was difficult or unsatisfactory & - & $5(6.8)$ \\
\hline Living too far & - & $4(5.4)$ \\
\hline Lack of courage or energy & - & $2(2.7)$ \\
\hline Wish for an psychologist external from the centre & - & $1(1.4)$ \\
\hline Other & - & $5(6.8)$ \\
\hline \multicolumn{3}{|l|}{ How many further appointments did the patient attend? n (\%) } \\
\hline 1 & $2(6.7)$ & - \\
\hline $2-5$ & $13(43.3)$ & - \\
\hline $5-10$ & $8(26.7)$ & - \\
\hline$>10$ & $5(16.7)$ & - \\
\hline Missing & $2(6.7)$ & - \\
\hline
\end{tabular}

${ }^{a}$ Percentages on no re-contact were derived from the number of patients who thought of re-contacting the onco-psychologist. 
$17(23.0 \%)$ of them had thought of re-contacting him (Table 4). This thought occurred mostly during $(\mathrm{n}=2$, $11.8 \%)$ and just after $(\mathrm{n}=5,29.4 \%)$ the medical treatment, or within a few months of the first appointment $(\mathrm{n}=$ $10,58.8 \%)$. The majority of the patients who did not re-contact the psychologist $(\mathrm{n}=38,51.4 \%)$ simply did not feel the need for psychological help. Furthermore, another psychologist already followed $6(8.1 \%)$ of these patients. Lack of time and distance from the clinic also influenced the choice of not pursuing the psychological support, with $5(6.8 \%)$ and $4(5.4 \%)$ patients in each case respectively. The dimension of unsatisfactory contact with the psychologist also explained the choice for $5(6.8 \%)$ patients.

\subsection{Expectations of the Systematic Consultation}

The survey also examined the patients' expectations about the systematic consultation. As shown in Table 5, the expectations judged as "very important" by the patients were about the assurance of support and help (46 patients, $44.2 \%$ ), the possibility to express their feelings over the cancer diagnostic (44 patients, $42.3 \%$ ). 40 (38.4\%) patients also looked for reassurance, $39(37.5 \%)$ to get further information on the disease and the treatments, and 37 (35.6\%) wished to talk about their fear over treatments additional to the surgery. The opportunity to talk about the difficulties they have over their self-image after the surgery or the treatments and to free themselves from the anguish of the surgery were also judged as very important by a similar proportion of patients (31.8 and 30.8\% respectively). Finally, the patients found it less important to learn the ways to communicate their diagnostic to relatives, or to talk about their fears of the partner's looking at them and their sexuality ( 31 , $29.8 \%$ and $25,24.0 \%$ respectively).

\section{Discussion}

Besides a primary role for the specialist physician in the psychological support of cancer patients [1], which is due to his important place in the patients' cancer treatment, a specific psycho-oncological intervention may also be of importance [22]. However, when this intervention is only suggested, only a part of the patients will ask for it. The aims of the study were two-fold: 1) to obtain a clearer insight on the needs for a psychological interview among breast cancer patients; 2) to assess which fraction of them will ask for a specific psycho-oncological follow-up. Up to now, psycho-oncological interventions have either been supportive clinical interviews, with no systematic questioning of the expectations of patients [19], or totally structured interviews with systematic check-lists [20]. The first approach does not question systematically the patient's needs. The second approach is too structured to allow patients to freely express their needs and expectations. Hence, in order to address these two issues, we have developed a psychological semi-structured interview that is systematically proposed to all inpatients during their stay for a breast cancer surgical intervention. In these interviews, patients can freely express their feelings about the type of support they expect from a psycho-oncological interview.

Table 5. Patients' expectations at the first psychological appointment.

\begin{tabular}{lcccccc} 
& $\begin{array}{c}\text { Very important } \\
\mathrm{n}(\%)\end{array}$ & $\begin{array}{c}\text { Important } \\
\mathrm{n}(\%)\end{array}$ & $\begin{array}{c}\text { Indifferent } \\
\mathrm{n}(\%)\end{array}$ & $\begin{array}{c}\text { Not really } \\
\text { important } \mathrm{n}(\%)\end{array}$ & $\begin{array}{c}\text { Not important } \\
\text { at all } \mathrm{n}(\%)\end{array}$ & $\begin{array}{c}\text { Total } \mathrm{n}=104 \\
(100 \%)\end{array}$ \\
\hline $\begin{array}{l}\text { Assurance of support and help } \\
\begin{array}{l}\text { Possibility to express feelings } \\
\text { over cancer diagnostic }\end{array}\end{array}$ & $46(44.2)$ & $24(23.1)$ & $12(11.5)$ & $3(2.9)$ & $2(1.9)$ & $87(83.7)$ \\
$\begin{array}{l}\text { Learn ways to communicate } \\
\text { diagnostic to relatives }\end{array}$ & $44(42.3)$ & $24(23.1)$ & $13(12.5)$ & $4(3.8)$ & $2(1.9)$ & $87(83.7)$ \\
$\begin{array}{l}\text { Free themselves from anguish of surgery } \\
\begin{array}{l}\text { Talk about difficulties over self-image } \\
\text { after surgery or treatments }\end{array}\end{array}$ & $32(30.8)$ & $29(27.9)$ & $16(15.4)$ & $4(3.8)$ & $3(2.9)$ & $84(80.8)$ \\
$\begin{array}{l}\text { Talk about fear of the partner looking } \\
\text { at them and of sexuality }\end{array}$ & $33(31.8)$ & $25(24.0)$ & $21(20.2)$ & $7(6.7)$ & $3(2.9)$ & $89(85.6)$ \\
$\begin{array}{l}\text { Get further information on disease } \\
\text { and treatments }\end{array}$ & $39(37.5)$ & $28(26.9)$ & $13(12.5)$ & $5(4.8)$ & $4(3.8)$ & $89(85.6)$ \\
$\begin{array}{l}\text { Look for reassurance } \\
\begin{array}{l}\text { Talk about fear of additional treatments } \\
\hline\end{array}\end{array}$ & $40(38.4)$ & $33(31.8)$ & $10(9.6)$ & $2(1.9)$ & $4(3.8)$ & $89(85.6)$ \\
\hline
\end{tabular}


We analysed this first meeting, all patients are free to pursue a further psycho-oncological support and we analyse the psychosocial and medical factors that are related to that choice.

Several features can be highlighted from this first interview. Firstly, patients expect principally from the interview a support for emotional expression and for reassurance, an opportunity to express their fears and to obtain complementary medical information on illness and treatment. Secondly, we can also identify the factors that predicted the search for psychological support: Those who accept further psychological care after hospitalization are among the youngest of the population and most often have a job. It thus seems that the sudden lifestyle change after cancer diagnosis, for those who are active professionals motivates psychological support seeking. Thirdly, the burden of the disease, that is increased in situations such as invasive surgical treatment (mastectomy) or when radiotherapy or chemotherapy is necessary, does not influence the psychological follow-up. Fourthly, requests for counselling on how to communicate with children or other family members are also not a priority for asking for an intervention by the psychologist. We and others have observed that these types of requests usually must come in a second step, after remission of the disease [23].

Furthermore, our survey shows that $28.8 \%$ of patients wish to consult a psychologist after the first consultation. These figures are in keeping with the data found in the literature. A research by Libert et al. (2006) in Belgium indicated that $78.8 \%$ of cancer patients wanted to be supported by medical specialists. Obtaining medical information and reassurance about vital prognosis of the disease motivates preferential search for medical support [1]. The support that physicians can provide has an important role in listening and discussing with their patients [24]. Furthermore, physicians are most often the only professionals to provide psychological care for patients [1].

Therefore, what is the role of the psycho-oncologist? It is important to understand the specificity of the psychologist in oncological units. In most situations, members of the multidisciplinary team and especially physicians are usually sufficient to provide emotional support to patients. The psychologist will intervene in situations where patients expect to obtain the assurance of a support in case of difficulty to cope with the cancer evolution, when they look for more reassurance about their fears. The psychologist will also be expected to provide the opportunity to the patients to express their feelings about their cancer and its consequences/after- maths. However, the study also supports that mainly a category of patients will ask for this type of psychological support: patients that are young and still active professionally. We hypothesise that for this category of patients, the psychologist has an important role in the psycho-social reintegration after the remission of cancer, as previous studies have pointed out [23] [25]. In the case of metastatic patients, the therapeutic process is also important in the adaptation to successive bereavements [26].

\section{Limitations}

Like many studies, this survey has some limitations. Firstly, it was based on a questionnaire designed by ourselves, which was aimed at evaluating our services. The use of validated tools would be more appropriate. Secondly, the breast cancer population was studied, but we would suggest studying patients with various types of cancer, and including both genders in order to better represent the systematic interview. Furthermore, a prospective study would also permit a better assessment and give more reliable results than a retrospective study.

\section{Recommendations}

In oncology, physicians are most often the only professionals to provide psychological care for patients. However, multidisciplinary work is in full development, and the psycho-oncologist, as a part of this multidisciplinary team has an important role in the emotional support during treatment and the psychosocial reintegration after the remission of cancer. A systematic consultation with a psychologist at entry may potentially also decrease negative stereotypes toward psychological help, improve therapeutic alliance and help patients to cope with their cancer-related biopsychosocial needs.

\section{References}

[1] Libert, Y., Merckaert, I., Etienne, A.-M., Farvacques, A., Liénard, A., Messin, J., Meunier, J., Milani, M., Moucheux, A., Reynaert, C., Salis, J., Slachmuylder, J.-L. and Razavi, D. (2006) Les besoins psychosociaux et le soutien apporté aux Patients atteints d'un Cancer: Une étude nationale Belge. Oncologie, 8, 465-476.

[2] Caraceni, A. and Portenoy, R.K. (1999) An International Survey of Cancer Pain Characteristics and Syndromes. Pain, 
82, 263-274.

[3] Kirsh, K.L., Passik, S., Holtsclaw, E., Donaghy, K. and Theobald, D. (2001) I Get Tired for No Reason: A Single Item Screening for Cancer-Related Fatigue. Journal of Pain and Symptom Management, 22, 931-937. http://dx.doi.org/10.1016/S0885-3924(01)00350-5

[4] Davis, M.P. and Walsh, D. (2000) Treatment of Nausea and Vomiting in Advanced Cancer. Support Care Cancer, 8, 444-452.

[5] Loge, J.H. and Abrahamsen, A.F. (1997) Psychological Distress after Cancer Cure: A Survey of 459 Hodgkin's Disease Survivors. British Journal of Cancer, 76, 791-796.

[6] Baider, L., Andritsch, E., Goldzweig, G., Uziely, B., Ever-Hadani, P., Hofman, G., Krenn, G. and Samonigg, H. (2004) Changes in Psychological Distress of 124 Brief Reports Women with Breast Cancer in Long-Term Remission and Their Husbands. Psychosomatics, 45, 58-68.

[7] Newell, S., Sanson-Fisher, R.W., Girgis, A. and Bonaventura, A. (1998) How Well Do Medical Oncologists' Perceptions Reflect Their Patients' Reported Physical and Psychosocial Problems? Data from a Survey of Five Oncologists. Cancer, 83, 1640-1684.

[8] Detmar, S.B., Aaronson, N.K., Wever, L.D.V., muller, M. and Schornagel, J.H. (2000) How Are You Feeling? Who Wants to Know? Patients' and Oncologists' Preferences for Discussing Health-Related Quality-of-Life Issues. Journal of Clinical Oncology, 18, 3295-3301.

[9] Sollner, W., DeVries, A, Steixner, E., Lukas, P., Sprinzl, G., Rumpold, G. and Maislinger, S. (2001) How Successful Are Oncologists in Identifying Patient Distress, Perceived Social Support, and Need for Psychosocial Counselling? British Journal of Cancer, 84, 179-185.

[10] Razavi, D., Delvaux, N., Marchal, S., De Cock, M., Farvacques, C. and Slaymuylder, J.-L. (2000) Testing Health Care Professionals' Communication Skills: The Usefulness of Highly Emotional Standardized Role-Playing Sessions with Simulators. Psycho-Oncology, 9, 293-302.

[11] Merckaert, I., Libert, Y., Delvaux, N. and Razavi, D. (2005) Breast Cancer: Communication with a Breast Cancer Patient and a Relative. Annals of Oncology, 16, 209-212. http://dx.doi.org/10.1093/annonc/mdi711

[12] Merckaert, I., Libert, Y., Delvaux, N., Marchal, S., Boniver, J., Etienne, A.M., Klastersky, J., Reynaert, C., Salliet, P., Slachmuylder, J.L. and Razavi, D. (2008) Factors Influencing Physicians' Detection of Cancer Patients' and Relatives' Distress: Can a Communication Skills Training Program Improve Physicians' Detection? Psycho-Oncology, 17, 260269. http://dx.doi.org/10.1002/pon.1233

[13] Nelis, D., Kotsou, I., Quoidbach, J., Hansenne, M., Weytens, F., Dupuis, P. and Mikolajczak, M. (2011) Increasing Emotional Competence Improves Psychological and Physical Well-Being, Social Relationships, and Employability. Emotion, 11, 354-366. http://dx.doi.org/10.1037/a0021554

[14] Watson, M. and Bultz, B.D. (2010) La détresse, sixième signe vital dans les soins du cancer: Être attentif aux besoins émotionnels des patients: Qu'Est-ce que ça veut dire et qu'est-ce qui est utile? Psycho-Oncologie, 4, 159-163.

[15] Ciaramella, A. and Poli, P. (2001) Assessment of Depression among Cancer Patients: The Role of Pain, Cancer Type and Treatment. Psycho-Oncology, 10, 156-165. http://dx.doi.org/10.1002/pon.505

[16] Hopwood, P., Sumo, G., Mills, J., Haviland, J. and Bliss, J.M. (2010) The Course of Anxiety and Depression over 5 Years of Follow-Up and Risk Factors in Women with Breast Cancer: Results from the UK Standardisation of Radiotherapy Trials. The Breast, 19, 84-91. http://dx.doi.org/10.1016/j.breast.2009.11.007

[17] So, W.K., Marsh, G., Ling, W.M., Leung, F.Y., Lo, J.C., Yeung, M. and Li, G.K. (2010) Anxiety, Depression and Quality of Life among Chinese Breast Cancer Patients during Adjuvant Therapy. European Journal of Oncology Nursing, 14, 17-22. http://dx.doi.org/10.1016/j.ejon.2009.07.005

[18] Onkelinx, L. (2008) Le Plan National Cancer. [Internet] http://health.belgium.be/eportal/Healthcare/Specialisedcare/CancerPlan/19080671?ie2Term=plan\%20cancer?\&fodnlan $\mathrm{g}=\mathrm{fr} \#$.VAd05EtJyBw

[19] Bramsen, I., Van der Linden, M., Eskens, F.J., Bijvank, E.M., van Groeningen, C.J., Kaufman, H.J. and Aaronson, N.K. (2008) Evaluation of a Face-to-Face Psychosocial Screening Intervention for Cancer Patients: Acceptance and Effects on Quality of Life. Patient Education and Counseling, 70, 61-68. http://dx.doi.org/10.1016/j.pec.2007.09.010

[20] Roth, A., Kornblith, A., Batel-Copel, L., Perbody, E., Scher, H. and Holland, J. (1998) Rapid Screening Distress in Men with Prostate Carcinoma: A Pilot Study. Cancer, 82, 1904-1908. http://dx.doi.org/10.1002/(SICI)1097-0142(19980515)82:10<1904::AID-CNCR13>3.0.CO;2-X

[21] Ogez, D. (2010) Supply and Demand in Psycho-Oncology: How the Psycho-Oncologist Can Support the Patients and Respect Their Choices. Psycho-Oncology, 19, 233.

[22] Andersen, B.L., Yang, H.C., Farrar, W.B., Golden-Kreutz, D.M., Emery, C.F., Thornton, L.M., Young, D.C. and 
Carson, W.E. (2008) Psychologic Intervention Improves Survival for Breast Cancer Patients. A Randomized Clinical Trial. Cancer, 113, 3450-3458. http://dx.doi.org/10.1002/cncr.23969

[23] Zelek, L., Bouillet, T., Latino-Martel, P., Pecollo, N., Barrandon, E., Czernichow, S., Galan, P and Hercberg, S. (2010) Mode de vie et cancer du sein: Quels conseils pour la prise en charge de l'après-cancer? Oncologie, 12, 289-297. http://dx.doi.org/10.1007/s10269-010-1878-7

[24] Razavi, D. and Delvaux, N. (1997) Communication Skills and Psychological Training in Oncology. European Journal of Cancer, 33, 15-21. http://dx.doi.org/10.1016/S0959-8049(97)00195-0

[25] Van Weert, E., Hoekstra-Weebers, J., Grol, B., Otter, R., Arendzen, H.J., Postema, K., Sanderman, R. and van der Schans, C. (2005) A Multidimensional Cancer Rehabilitation Program for Cancer. Journal of Psychosomatic Research, 58, 485-496. http://dx.doi.org/10.1016/j.jpsychores.2005.02.008

[26] Bacqué, M.F. (2000) Le deuil à vivre. Odile Jacob, Paris. 
Scientific Research Publishing (SCIRP) is one of the largest Open Access journal publishers. It is currently publishing more than 200 open access, online, peer-reviewed journals covering a wide range of academic disciplines. SCIRP serves the worldwide academic communities and contributes to the progress and application of science with its publication.

Other selected journals from SCIRP are listed as below. Submit your manuscript to us via either submit@scirp.org or Online Submission Portal.
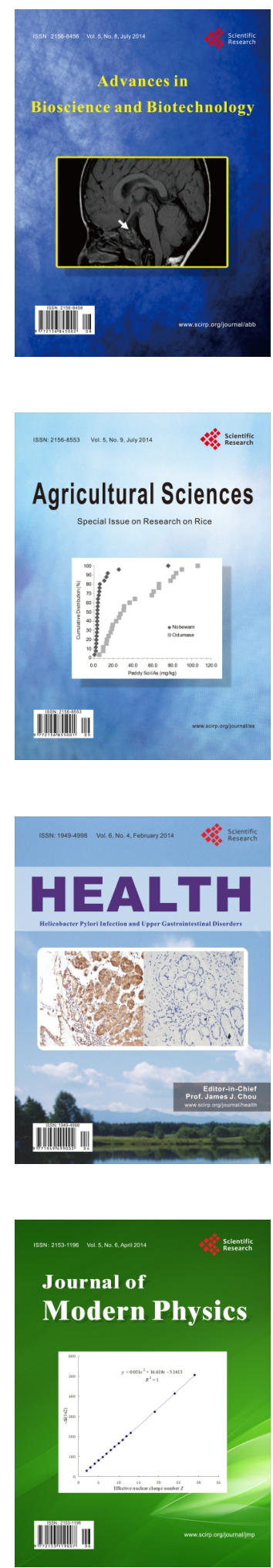
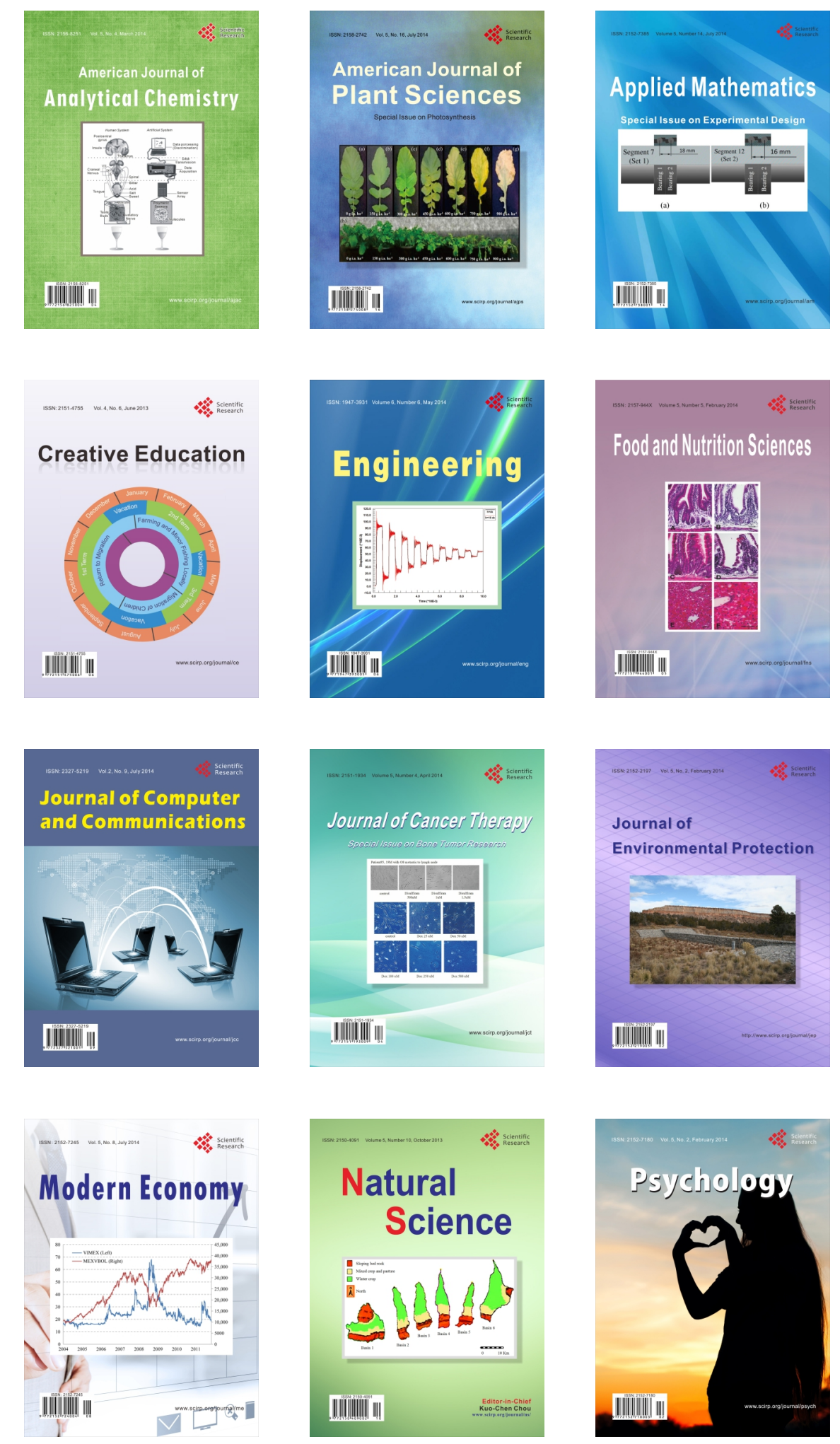